\title{
Psychological resources in adolescence and the association with labour market participation in early adulthood: A prospective cohort study
}

Jacob Devantie Jensen

Ramboll Management Consulting

Johan Hviid Andersen

Department of Occupational Medicine, Danish Ramazzini Centre, University Research Clinic, Regional Hospital West Jutland

Trine Nøhr Winding ( $\nabla$ trwind@rm.dk)

Department of Occupational Medicine, Danish Ramazzini Centre, University Research Clinic, Regional Hospital West Jutland

Research article

Keywords: Labour market participation, adolescents, personal mastery, self-esteem, sense of coherence

Posted Date: November 26th, 2019

DOI: https://doi.org/10.21203/rs.2.17805/v1

License: (c) (i) This work is licensed under a Creative Commons Attribution 4.0 International License. Read Full License

Version of Record: A version of this preprint was published at BMC Public Health on March 24th, 2020. See the published version at https://doi.org/10.1186/s12889-020-08531-w. 


\section{Abstract}

Background: Young adults at the age of 25-29 have the highest unemployment rate and are in great risk of labour market marginalization. Exclusion from the labour market may have negative individual consequences on mental and physical health and can lead to increasing societal expenditures due to social benefits. It is important to understand what factors determine or protect against early labour market marginalization. The aim of the present study was to investigate the association between psychological resources in adolescence and labour market participation in early adulthood, and whether the associations differed by gender.

Methods: This prospective cohort study used questionnaire data collected through the West Jutland Cohort study in 2004 and 2007. The study population $(\mathrm{N}=2,982)$ consisted of people born in 1989 and living in the county of Ringkjoebing at baseline in 2004. Outcome was dichotomized as $+/-12$ months of passive labour market participation during the age of 25-29. Psychological resources were measured as self-esteem, sense of coherence and mastery. Logistic regression analyses were performed to investigate the associations between psychological resources and labour market participation.

Results: Results indicated associations between high levels of mastery or sense of coherence in adolescence and high labour market participation in early adulthood. The strongest associations were observed for females with a medium (OR: 1.9) or high level (OR: 1.6) of mastery or a high level of sense of coherence (OR: 1.6) at age 15 and for males with a medium (OR: 2.7) or high (OR: 1.9) level of mastery or a high level of sense of coherence (OR:1.7) at age 18. The associations between adolescent selfesteem and labour market participation were modest at both ages.

Conclusion: The results of the present study indicate associations between a high level of sense of coherence or mastery in adolescence and high labour market participation in early adulthood. Psychological resources seemed to play a bigger role for females in early adolescence compared to males, for whom a larger impact was seen in late adolescence. Further studies are needed to elaborate the properties of these observed differences by gender and period of adolescence.

\section{Background}

In February 2019 the general unemployment rate in Denmark was $3.7 \%$, however it was $7 \%$ for 25-29year-olds [1]. Labour market marginalization among young adults is of rising concern due to the related negative health consequences [2]. Young adults outside the labour market show a higher risk of psychological vulnerability and distress and feel affected by insecurities about their own capabilities [3]. Stability of attachment to the labour force during the transitional period into working life is of great importance, as it improves the future job prospects and avoids the dependency on social benefits [4]. Furthermore, people who experience unemployment early in life are at greater risk of experiencing unemployment across the life course [5-9]. The entrance into the labour market in early adulthood is 
therefore an important part of the general life course development and it is important to study the determinants of facilitating labour market participation (LMP) in early adulthood.

Previous studies show clear associations between socioeconomic status such as low income or educational level in the family, psychiatric disorders, the experience of negative life events, somatic complaints during adolescence and the risk of an unstable entrance into the labour market in early adulthood [10-14]. Furthermore, indications point towards mental health and psychological vulnerability affecting the early work environment [15]. Many studies focus on the effect of unemployment on mental health factors. However, few studies focus on the resilient perspective of psychological factors as resources in facilitating LMP.

Adolescence is a key-developmental stage of both physical, neurological, psychological and social changes and have immense impact on later health outcomes leaving some individuals more vulnerable than others [16]. Psychological resources appear to develop across the entire life span, with both selfesteem $[17,18]$, personal mastery $[19]$ and sense of coherence $[20,21]$ being at their lowest point during adolescence. Furthermore, gender seems to be a contributing factor in the level of self-esteem, personal mastery and sense of coherence, where males generally show a higher level, independent of age $[19,20$, 22]. Psychological resources are important factors of general health and can act as protective determinants during life course transitions [23].

Psychological resources such as self-esteem and sense of coherence (SOC) have shown to be facilitating factors of entering the labour market. However, they are also affected negatively by staying excluded from the labour market; the exact causal effect yet remains controversial [17, 24-26]. Research suggests an association between a lower level of sense of coherence and the risk of receiving social benefits in young adulthood [27]. Adolescents with a low level of self-esteem have shown to attain lower levels of education and are less likely to be employed 14-years after leaving high-school [28]. People with higher self-esteem seem to handle negative life events better [29], and show greater success in the initial job search [30]. A sense of mastery reduces psychological distress and act as a protective agent against stressful life events. In addition, a sense of mastery seems to be a mediating factor between the role of social class and economic hardship and health later in life [31-33].

A high level of SOC seems to be related to positive perceived health and show strong inverse associations with psychological symptoms like depression and anxiety [34]. The association between self-esteem and depression has been extensively studied, showing a strong association between low self-esteem and depression, however, the causal link is broadly debated [35]. Research in regard to mastery has focused more on the mediating role of mastery on depression, and higher levels of mastery indicate lower risk of depression [36]. People from lower levels of socioeconomic status, most strongly related to income and education, generally appear to have lower levels of self-esteem, sense of coherence and mastery $[19,37$, 38].

The existing knowledge on the link between psychological resources of self-esteem, mastery and sense of coherence in adolescence and LMP in early adulthood is sparse. Given the nature and existing 
knowledge of the harmonious facilitating capabilities of these psychological resources, they ensure potential in advancing LMP in early adulthood. The present study seeks to investigate the associations between self-esteem, sense of coherence or mastery at age 15 and 18 and LMP in early adulthood at age 25-29. Furthermore, the study aims to investigate a potential gender difference in the associations between these psychological resources and LMP.

\section{Methods}

\section{Study population}

The study population was derived from the West Jutland Cohort study, which is a project focusing on studying and exploring different aspects of inequalities and social disparities on general health and well-being development in a life course perspective [39]. The West Jutland Cohort is a follow-up study of 3,681 individuals, who were born in 1989 and living in the western part of Jutland, Denmark in 2004 [11, 40]. The recruitment took place at the schools within the county of Ringkjoebing, subsequently the children who were not at school received the questionnaire by mail. From the original source population $(n=3,681)$, 3,054 (83 \%) adolescents (age 15) participated in filling out the baseline questionnaire in 2004 [40]. A follow-up questionnaire was distributed by postal service and mail in 2007 when the adolescents were 18 years-old. The follow-up resulted in 2,181 participants (71 \% of the initial study population). However, since the follow-up questionnaire was distributed to all 3,681 individuals from the source population, 219 new respondents participated. The final study population for the present study included baseline participants with questionnaire information on psychological resources at age 15 and/or 18 with register information on LMP in the period between the age of 25-29 $(n=2,982)$.

\section{Outcome}

The information of the outcome for the present study was obtained from the Danish Register for Evaluation and Marginalization (DREAM)[41]. The DREAM register includes information on social benefits such as unemployment benefits, sickness benefits and disability benefits on a weekly basis on all Danish citizens. Information about social benefits for a 204-week period was collected from $1^{\text {st }}$ of January 2015 to $2^{\text {nd }}$ of December 2018, when the participants were 25-29 years old. For all participants, weeks not receiving any 
benefits at all, or receiving maternity leave benefits, state educational benefits or supplementary unemployment benefits were classified as "active LMP". On the contrary weeks of labour market exclusion receiving all other kinds of social benefits were classified as "passive LMP". Based on the total number of weeks with passive LMP during the 4 years period, participants were dichotomized into 'Low LMP' if they had received $\geq 12$ months of passive LMP or 'High LMP' if they had received $<12$ months of passive LMP. The register information was merged with questionnaire data by the Danish CPR-number which every Danish inhabitant possesses [42].

\section{Exposure variables}

In the present study, psychological resources were measured as the theoretical concepts of self-esteem, mastery and sense of coherence. Information on these resources was obtained through questionnaire data in 2004 (age 15) and 2007 (age 18). The three variables were collected through subscales of earlier validated questionnaires; sense of coherence (Antonovsky's sense of coherence scale) [43], personal mastery (Pearlin \& Schooler) [44] and self-esteem (Rosenberg's Self-esteem scale)[45]. The full scales were not included for sense of coherence and self-esteem. The included scales are described in table 1.

Table 1: Exposure items from the included scales to measure psychological resources 
Items

Sense of coherence (Meaningfulness)

1. What do you think of the things you do every day?

2. How often do you do things that you find meaningful?

3. How often do you feel, that you don't care about what goes on around you?

4. How often do you have the feeling that there is little meaning in the things you do in your daily life?

\section{Scale}

Total score sums between 4-20

"Very boring" (1) - "Very exciting"

(5)

"Never" (1) - "Very often" (5)

"Very often" (1) - "Never" (5)

"Very often" (1) - "Never" (5)
Personal mastery

1. I have little control of the things that happen to me.

2. There is really no way I can solve some of the problems I have

3. There is little I can do to change many of the important things in my life

4. I often feel helpless in dealing with problems of life

5. Sometimes I feel that I'm being pushed around in life

6. What happens in the future mostly depends on me

7. I can do just about anything I really set my mind to do

Self-esteem

1. I feel that I have a number of good qualities

2. I feel that I'm a person of worth at least equal to others

3. I am able to do things as well as most other people

4. I take a positive attitude toward myself

5. On a whole, I am satisfied with myself

6. All in all, I'm inclined to feel that I'm a failure
Total score sums between 7-28

"Strongly disagree" (1) - "Strongly agree" (4)

"Strongly disagree" (1) - "Strongly agree" (4)

"Strongly disagree" (1) - "Strongly agree" (4)

"Strongly disagree" (1) - "Strongly agree" (4)

"Strongly disagree" (1) - "Strongly agree" (4)

"Strongly disagree" (1) - "Strongly agree" (4)

"Strongly disagree" (1) - "Strongly agree" (4)

Total score sums between 6-24

"Strongly disagree" (1) - "Strongly agree" (4)

"Strongly disagree" (1) - "Strongly agree" (4)

"Strongly disagree" (1) - "Strongly agree" (4)

"Strongly disagree" (1) - "Strongly agree" (4)

"Strongly disagree" (1) - "Strongly agree" (4)

"Strongly agree" (1) - "Strongly disagree" (4)

\section{Sense of coherence was measured using Antonovsky's "Sense of coherence scale - Revised}

short version for children" $[43,46]$. For the present study, only the subscale of the original questionnaire measuring the sense of meaningfulness including 4 items of the total 13 was used. The sense of coherence scale has been widely studied and has shown good validity across cultures [46]. The level of mastery was measured using Pearlin \& Schooler's Personal mastery 7-item scale, which has shown strong structural validity [44]. The self- 
esteem measure was derived from Rosenberg's 10 item self-esteem scale [45]. Six items of the original 10 item scale were used. Turner et. al previously used this particular subscale for measuring self-esteem [47]. For analysis all exposure variables were categorized into tertiles at $33 \%$ and $66 \%$.

\section{Covariates}

Independent variables included socioeconomic background defined by two perspectives: Equivalized household income and highest attained parental level of education. Equivalized household income was calculated from a yearly average of a 4-year period when the children were 7-10 years old. Equivalized income is a weighted average calculation divided by the number of household members based on a weight of 1.0 for the first adult, 0.5 for the second adult and persons above 14 years of age and lastly 0.3 for children below the age of 14 [48]. Income was recoded into tertiles corresponding to low $(<11072 €)$, medium (11072-13489 €), and high (>13489 €) yearly equivalized average income. Equivalized income average was only calculated if respondents did not miss more than 1 year of information regarding income. Highest attained parental level of education was obtained in year 2004 and categorized by primary level of education (<10 years), secondary level (1013 years) and tertiary level (>13 years) of education. Information about socioeconomic factors was derived using information from the Central Office of Civil Registration (CPR) from the national registers in Statistics Denmark. In the register, the children are linked to their parents by their personal CPR-number [42]. These measures of socioeconomic factors have previously been validated $[49,50]$.

Further covariates in the analyses were: self-reported information about self-rated health, depressive symptoms and negative life events. Self-rated health was measured using a single question: "In general, how would you rate your health?" on a scale from 1 "poor" to 5 "excellent" health, derived from the SF-36 questionnaire [51]. The measure of self-rated health was dichotomized with (1-3) indicating poor self-rated health and (4-5) indicating good self-rated health. Self-rated health was measured at age 15 and 18. Depressive symptoms were similarly measured at both ages using the 4-item version of Centre for 
Epidemiological Studies Depression Scale for Children (CES-DC) providing a score of 0-12. In analyses the CES-DC score was included as a continuous variable, with higher scores indicating a higher level of depressive symptoms [52]. Negative life events were measured at age 15 using 6 items from a 13-item scale of Newcomb et al [53]. The scale and data of the measure of negative life events in the West Jutland Cohort study was previously described and analyzed in relation to LMP [10]. Three categories were made for analysis: 0 events, 1-2 events and 3-6 events.

\section{Statistical analysis}

Baseline descriptive statistics of the study population in total and for males and females separately was performed and presented for all outcome, exposure and covariate variables as number and percentile distribution.

Multiple logistic regressions were used to study the associations between the exposure variables and outcome of LMP. All analyses were performed for the total population and stratified by gender. Covariates included in the analyses were chosen a priori based upon existing literature. For studying the associations between psychological resources and LMP, three models were constructed.

First, a crude model examining the association of psychological resources and all covariates with LMP was performed independently. Secondly (model 1), independent analyses for the exposure variables of the psychological resources adjusting for the adolescents' highest parental level of education and equivalized household income was performed. Lastly (model 2), the fully adjusted analysis was performed independently for each exposure variable adjusting for all additional covariates. All odds ratio estimates for (model 2 ) were presented with $95 \%$ confidence intervals with a significance level of $p<$ 0.05. All calculations and analyses were carried out using STATA Statistical Data Package 15.1.

\section{Ethics}

Use of the data was carried out under the same conditions and with the same purpose as originally collected. The study was approved by the Danish Data Protection Agency, according to Danish law for studies using questionnaire and register data (The Act on Processing of Personal Data - Act No. 429 of 31 May 2000). Written informed consent was not required in questionnaire or register-based projects. 


\section{Results}

Table 2 shows the characteristics of the final study population regarding exposure, outcome and covariates included in further analysis. From the final study population of 2,982 participants, 2,591 (87\%) had a high level of LMP and 391 (13\%) a low level of LMP. More females compared to males had a low LMP. In general, males reported having higher levels on all psychological resources, except for sense of coherence at age 15. The remaining covariates also demonstrated gender differences with males reporting the highest levels of self-rated health and the lowest levels of depressive symptoms and number of negative life events. No gender differences were seen regarding equivalized household income or highest parental education. 
Table 2: Descriptive statistics of the study population $(n=2982)$

\begin{tabular}{|c|c|c|c|c|c|c|c|}
\hline & \multirow{2}{*}{$\begin{array}{c}\mathrm{Age}^{1} \\
25-29\end{array}$} & \multicolumn{2}{|c|}{$\begin{array}{l}\text { Total } \\
\mathrm{n}(\%) \text { or mean (SD) }\end{array}$} & \multicolumn{2}{|c|}{$\begin{array}{l}\text { Males } \\
\mathrm{n}(\%) \text { or mean }(\mathrm{SD})\end{array}$} & \multicolumn{2}{|c|}{$\begin{array}{l}\text { Females } \\
\mathrm{n}(\%) \text { or mean }(\mathrm{SD})\end{array}$} \\
\hline & & 2982 & & 1485 & & 1497 & \\
\hline High & & 2591 & (87) & 1325 & (89) & 1266 & (85) \\
\hline Low & & 391 & (13) & 160 & (11) & 231 & (15) \\
\hline SOC & 15 & 2967 & & 1477 & & 1490 & \\
\hline High & & 851 & (29) & 386 & $(26)$ & 465 & (31) \\
\hline Medium & & 1138 & (38) & 581 & (39) & 557 & (37) \\
\hline Low & & 978 & (33) & 510 & (35) & 468 & (31) \\
\hline SOC & 18 & 2149 & & 986 & & 1163 & \\
\hline High & & 686 & (34) & 313 & (34) & 402 & (32) \\
\hline Medium & & 725 & (34) & 340 & (34) & 388 & (33) \\
\hline Low & & 735 & (32) & 333 & (32) & 373 & (35) \\
\hline Mastery & 15 & 2930 & & 1468 & & 1462 & \\
\hline High & & 936 & (32) & 513 & (35) & 423 & (29) \\
\hline Medium & & 1193 & $(40)$ & 615 & $(42)$ & 578 & $(40)$ \\
\hline Low & & 801 & $(27)$ & 340 & (23) & 461 & (32) \\
\hline Mastery & 18 & 2088 & & 953 & & 1135 & \\
\hline High & & 658 & (32) & 318 & (33) & 340 & (30) \\
\hline Medium & & 734 & (35) & 349 & (37) & 385 & (33) \\
\hline Low & & 696 & (33) & 286 & $(30)$ & 410 & (36) \\
\hline Self-esteem & 15 & 2932 & & 1466 & & & \\
\hline High & & 1234 & $(42)$ & 736 & $(50)$ & 498 & (34) \\
\hline Medium & & 975 & (33) & 502 & $(34)$ & 473 & (32) \\
\hline Low & & 723 & $(25)$ & 228 & $(16)$ & 495 & (34) \\
\hline Self-esteem & 18 & 2154 & & 991 & & 1163 & \\
\hline High & & 839 & (39) & 491 & $(50)$ & 348 & $(43)$ \\
\hline Medium & & 573 & $(27)$ & 255 & $(26)$ & 318 & $(27)$ \\
\hline Low & & 742 & $(34)$ & 245 & $(25)$ & 497 & (30) \\
\hline Household income & $7-10$ & 2982 & & 1485 & & 1497 & \\
\hline High $(<13489 €)$ & & 1082 & $(36)$ & 548 & $(37)$ & 534 & (36) \\
\hline Middle (11072 - $13489 €)$ & & 999 & $(34)$ & 498 & (34) & 501 & (33) \\
\hline Low $(<11072 €)$ & & 901 & $(36)$ & 439 & $(30)$ & 462 & $(31)$ \\
\hline Parents' highest education & & 2875 & & 1434 & & 1441 & \\
\hline Primary (>10 years) & & 358 & $(12)$ & 177 & $(12)$ & 181 & (13) \\
\hline Secondary (10-12 years) & & 1366 & $(48)$ & 659 & $(46)$ & 707 & $(49)$ \\
\hline Tertiary (>12 years) & & 1151 & $(40)$ & 598 & $(42)$ & 553 & (38) \\
\hline Depressive symptoms, mean (SD) & 15 & 2.2 & $(2.2)$ & 1.9 & $(1.9)$ & 2.5 & $(2.4)$ \\
\hline Depressive symptoms, mean (SD) & 18 & 2.9 & $(2.3)$ & 2.4 & $(2.1)$ & 3.2 & $(2.4)$ \\
\hline Self-rated health (SRH) & 15 & 2963 & & 1472 & & 1491 & \\
\hline Good & & 2213 & $(75)$ & 1178 & $(80)$ & 1035 & (69) \\
\hline Poor & & 750 & $(25)$ & 294 & $(20)$ & 456 & (31) \\
\hline Self-rated health (SRH) & 18 & 2147 & & 984 & & 1163 & \\
\hline Good & & 1383 & $(64)$ & 714 & (73) & 669 & (58) \\
\hline Poor & & 764 & (36) & 270 & $(27)$ & 494 & $(42)$ \\
\hline Negative life events & 15 & 2928 & & 1468 & & 1460 & \\
\hline No events & & 1772 & $(61)$ & 918 & (63) & 854 & $(58)$ \\
\hline
\end{tabular}




\begin{tabular}{lllllll}
$1-2$ events & 1026 & $(35)$ & 499 & $(34)$ & 527 & (36) \\
\hline $3-6$ events & 130 & $(4)$ & 51 & $(3)$ & 79 & $(5)$ \\
\hline
\end{tabular}

1: Age of respondents when data was collected; SD standard deviation

Table 3 presents the analysis of psychological resources at the age of 15 and their impact on LMP in early adulthood. Overall, strong associations between all measures of psychological resources and LMP were observed in the crude models. The associations between psychological resources and LMP were all weakened, when adjusting for additional covariates. The association between mastery and LMP in the fully adjusted analysis (model 2) only remained strong for females with medium (OR: 1.9, 95 \% CI: 1.32.8) and high (OR: 1.6, 95 \% CI: 1.02-2.4) mastery compared to a low level of mastery. Furthermore, a high level of sense of coherence revealed a positive association with high LMP for females (OR: 1.6 - 95\% CI: 1.01-2.4). Positive associations between mastery or self-esteem and LMP were present in model 1 for males but diminished when adjusting for all covariates.

Table 4 presents the analysis of psychological resources at the age of 18 and their impact on LMP in early adulthood. The crude analysis showed similar results of table 3 with overall strong associations between measures of psychological resources and LMP. Mastery presented positive associations with a high LMP for males at a medium (OR: 2.7, 95\% CI: 1.5 - 3.8) and high (OR: 1.9, 95\% CI: 1.1 - 3.5) level of mastery. Female mastery showed minor associations between medium or high mastery and high LMP compared to low mastery. A positive association between a high level of sense of coherence and LMP was present for the total study population in the fully adjusted analysis (OR: 1.5, 95\% CI: $1.04-2.2$ ), and when splitting on gender positive associations were still present for both males (OR: 1.7, 95\% CI: 0.9 - 3.1) and females (OR: 1.4, 95\% CI: 0.9 - 2.3). 
Table 3: Psychological resources at age 15 and less than 12 months of passive labour market participation at age 25-29

\begin{tabular}{|c|c|c|c|c|c|c|c|c|c|c|c|}
\hline \multicolumn{4}{|c|}{ Total } & \multicolumn{4}{|c|}{ Males } & \multicolumn{4}{|c|}{ Females } \\
\hline Crude $^{1}$ & Model & Model & $95 \%$ & Crude $^{1}$ & Model & Model & $95 \%$ & Crude $^{1}$ & Model & Model & $95 \%$ \\
\hline & $1^{\mathrm{a}}$ & $2^{b}$ & $\mathrm{CI}^{\mathrm{c}}$ & & $1^{\mathrm{a}}$ & $2^{b}$ & $\mathrm{CI}^{\mathrm{c}}$ & & $1^{\mathrm{a}}$ & $2^{b}$ & $\mathrm{CI}^{\mathrm{c}}$ \\
\hline
\end{tabular}

\section{Total}

Sense of coherence

\begin{tabular}{|c|c|c|c|c|c|c|c|c|c|c|c|c|}
\hline Low & (ref.) & (ref.) & (ref.) & & (ref.) & (ref.) & (ref.) & & (ref.) & (ref.) & (ref.) & \\
\hline Medium & 1.4 & 1.3 & 1.2 & $\begin{array}{l}(0.9- \\
1.5)\end{array}$ & 1.4 & 1.2 & 1.1 & $\begin{array}{l}(0.7- \\
1.7)\end{array}$ & 1.5 & 1.4 & 1.3 & $\begin{array}{l}(0.9- \\
1.9)\end{array}$ \\
\hline High & 1.7 & 1.5 & 1.2 & $\begin{array}{l}(0.9- \\
1.7)\end{array}$ & 1.5 & 1.3 & 1.1 & $\begin{array}{l}(0.7- \\
1.7)\end{array}$ & 2.0 & 1.8 & 1.6 & $\begin{array}{r}(1.01 \\
-2.4)\end{array}$ \\
\hline
\end{tabular}

Mastery

\begin{tabular}{|c|c|c|c|c|c|c|c|c|c|c|c|c|}
\hline Low & (ref.) & (ref.) & (ref.) & & (ref.) & (ref.) & (ref.) & & (ref.) & (ref.) & (ref.) & \\
\hline Medium & 1.8 & 1.9 & 1.6 & $\begin{array}{l}(1.2- \\
2.1)\end{array}$ & 1.3 & 1.4 & 1.2 & $\begin{array}{l}(0.7- \\
1.8)\end{array}$ & 2.1 & 1.4 & 1.9 & $\begin{array}{l}(1.3- \\
2.8)\end{array}$ \\
\hline High & 2.1 & 1.9 & 1.4 & $\begin{array}{l}(1.04- \\
2.0)\end{array}$ & 1.7 & 1.6 & 1.2 & $\begin{array}{l}(0.7- \\
2.0)\end{array}$ & 2.1 & 1.8 & 1.6 & $\begin{array}{l}(1.0- \\
2.4)\end{array}$ \\
\hline
\end{tabular}

Self-esteem

\begin{tabular}{|c|c|c|c|c|c|c|c|c|c|c|c|c|}
\hline Low & (ref.) & (ref.) & (ref.) & & (ref.) & (ref.) & (ref.) & & (ref.) & (ref.) & (ref.) & \\
\hline Medium & 1.3 & 1.3 & 1.01 & $\begin{array}{l}(0.8- \\
1.4)\end{array}$ & 1.2 & 1.3 & 0.97 & $\begin{array}{l}(0.6- \\
1.6)\end{array}$ & 1.3 & 1.2 & 1.0 & $\begin{array}{l}(0.7- \\
1.5)\end{array}$ \\
\hline High & 1.7 & 1.6 & 1.2 & $\begin{array}{l}(0.9- \\
1.7)\end{array}$ & 1.6 & 1.7 & 1.2 & $\begin{array}{l}(0.7- \\
2.1)\end{array}$ & 1.5 & 1.3 & 1.1 & $\begin{array}{l}(0.7- \\
1.6)\end{array}$ \\
\hline
\end{tabular}

Equivalized

household income

$\begin{array}{clll}\text { Low }(<11072 €) & \text { (ref.) } & \text { (ref.) } & \text { (ref.) } \\ \text { Medium }(11072- & 1.1 & 1.3 & 1.04 \\ 13489 €) & & & 1.5\end{array}$

Parents highest

education

$\begin{array}{llll}\text { Primary }(<10 & \text { (ref.) } \quad \text { (ref.) } & \text { (ref.) }\end{array}$

years)

Secondary (10-12 2.1

$3.0+1.7$

years)

$\begin{array}{llll}\text { Tertiary }(>12 & 2.4 & 3.0 & 2.0\end{array}$

years)
Depressive
0.9
0.9
0.9

symptoms, age 15

Self-rated health,

age 15

$\begin{array}{llll}\text { Poor } & \text { (ref.) } & & \\ \text { Good } & 1.7 & 1.7 & 1.6\end{array}$

Negative life-events,

age 15

\begin{tabular}{llll}
\hline $3-6$ events & (ref.) & & \\
\hline $1-2$ events & 1.5 & 2.0 & 1.2 \\
\hline 0 events & 2.6 & 3.9 & 1.9 \\
\hline
\end{tabular}


1: Crude estimates for all included variables. a: Model 1: Psychological resources (sense of coherence, mastery and self-esteem) individually adjusted for equivalized household income and parent's highest education b: Model 2: Psychological resources individually adjusted for all included covariates, c: Confidence intervals (95 \%) presented for the fully adjusted analysis (model 2) 
Table 4: Psychological resources at age 18 and less than 12 months of passive labour market participation at age 25-29

\begin{tabular}{|c|c|c|c|c|c|c|c|c|c|c|c|c|}
\hline & \multicolumn{4}{|c|}{ Total } & \multicolumn{4}{|c|}{ Males } & \multicolumn{4}{|c|}{ Females } \\
\hline & Crude $^{1}$ & Model & Model & $95 \%$ & Crude $^{1}$ & Model & Model & $95 \%$ & Crude $^{1}$ & Model & Model & $95 \%$ \\
\hline & & $1^{\mathrm{a}}$ & $2^{b}$ & $\mathrm{CI}^{\mathrm{c}}$ & & $1^{\mathrm{a}}$ & $2^{b}$ & $\mathrm{CI}^{\mathrm{c}}$ & & $1^{\mathrm{a}}$ & $2^{b}$ & $\mathrm{CI}^{\mathrm{c}}$ \\
\hline \multicolumn{13}{|l|}{ Total } \\
\hline \multicolumn{13}{|c|}{ Sense of coherence } \\
\hline Low & (ref.) & (ref.) & (ref.) & & (ref.) & (ref.) & (ref.) & & (ref.) & (ref.) & (ref.) & \\
\hline Medium & 1.5 & 1.4 & 1.2 & $\begin{array}{l}(0.9- \\
1.6)\end{array}$ & 1.8 & 1.4 & 1.2 & $\begin{array}{l}(0.7- \\
2.0)\end{array}$ & 1.3 & 1.3 & 1.2 & $\begin{array}{l}(0.8- \\
1.8)\end{array}$ \\
\hline High & 2.0 & 2.0 & 1.5 & $\begin{array}{l}(1.04- \\
2.2)\end{array}$ & 2.5 & 2.4 & 1.7 & $\begin{array}{l}(0.9- \\
3.1)\end{array}$ & 1.7 & 1.8 & 1.4 & $\begin{array}{l}(0.9- \\
2.3)\end{array}$ \\
\hline \multicolumn{13}{|l|}{ Mastery } \\
\hline Low & (ref.) & (ref.) & (ref.) & & (ref.) & (ref.) & (ref.) & & (ref.) & (ref.) & (ref.) & \\
\hline Medium & 2.6 & 2.4 & 1.9 & $\begin{array}{l}(1.3- \\
2.7)\end{array}$ & 3.7 & 3.4 & 2.7 & $\begin{array}{l}(1.5- \\
3.8)\end{array}$ & 2.0 & 1.9 & 1.5 & $\begin{array}{l}(0.95 \\
-2.3)\end{array}$ \\
\hline High & 2.4 & 2.2 & 1.7 & $\begin{array}{l}(1.2- \\
2.5)\end{array}$ & 2.9 & 2.5 & 1.9 & $\begin{array}{l}(1.1- \\
3.5)\end{array}$ & 2.0 & 2.0 & 1.5 & $\begin{array}{l}(0.9- \\
2.5)\end{array}$ \\
\hline \multicolumn{13}{|l|}{ Self-esteem } \\
\hline Low & (ref.) & (ref.) & (ref.) & & (ref.) & (ref.) & (ref.) & & (ref.) & (ref.) & (ref.) & \\
\hline Medium & 1.2 & 1.2 & 0.9 & $\begin{array}{l}(0.7- \\
1.3)\end{array}$ & 1.3 & 1.2 & 0.99 & $\begin{array}{l}(0.6- \\
1.8)\end{array}$ & 1.1 & 1.1 & 0.9 & $\begin{array}{l}(0.6- \\
1.4)\end{array}$ \\
\hline High & 1.8 & 1.7 & 1.2 & $\begin{array}{l}(0.8- \\
1.6)\end{array}$ & 2.0 & 1.8 & 1.2 & $\begin{array}{l}(0.7- \\
2.1)\end{array}$ & 1.5 & 1.5 & 1.05 & $\begin{array}{l}(0.7- \\
1.7)\end{array}$ \\
\hline
\end{tabular}

Equivalized

household income

$\begin{array}{clll}\text { Low }(<11072 €) & \text { (ref.) } & \text { (ref.) } & \text { (ref.) } \\ \begin{array}{c}\text { Medium }(11072- \\ 13489 €)\end{array} & 1.1 & 1.3 & 1.0 \\ \text { High }(>13489 €) & 1.6 & 1.7 & 1.5\end{array}$

Parents highest

education

$\begin{array}{llll}\text { Primary }(<10 & \text { (ref.) } \quad \text { (ref.) } & \text { (ref.) }\end{array}$

years)

Secondary $(10-12 \quad 2$

years)

$\begin{array}{llll}\begin{array}{c}\text { Tertiary }(>12 \\ \text { years })\end{array} & 2.4 & 3.0 & 2.0\end{array}$

years)

$\begin{array}{llll}\text { Depressive } & 0.9 & 0.9 & 0.9\end{array}$

symptoms, age 18

Self-rated health,

age 18

$\begin{array}{ll}\text { Poor } & \text { (ref.) } \\ \text { Good } & 1.9\end{array}$

Negative life-events,

age 15

\begin{tabular}{llll}
\hline 3-6 events & (ref.) & & \\
\hline $1-2$ events & 1.5 & 2.0 & 1.2 \\
\hline 0 events & 2.6 & 3.9 & 1.9 \\
\hline
\end{tabular}


1: Crude estimates for all included variables. a: Model 1: Psychological resources (sense of coherence, mastery and self-esteem) individually adjusted for equivalized household income and parent's highest education b: Model 2: Psychological resources individually adjusted for all included covariates, c: Confidence intervals (95\%) presented for the fully adjusted analysis (model 2).

\section{Discussion}

Overall, the results showed positive associations between high levels of psychological resources and a high level of LMP, with mastery and sense of coherence showing the strongest associations. Mastery and sense of coherence seemed to operate differently for both genders at different ages. Generally, the highest impact was seen for females at the age of 15 and for males at age 18.

The literature on the impact of self-esteem, sense of coherence and mastery in adolescence on later LMP is scarce. The present study found no substantial associations between self-esteem and LMP, which is in line with Orth et al. indicating that self-esteem does not predict trajectories of occupational status [26]. This however contradicts the results of Waddell [28] indicating that self-esteem displays a role in attaining employment 14 -years after leaving high school. However, differences in study designs in relation to the construct and measurement method of LMP did compromise the comparability [28]. However, a possible explanation to the contradicting results could be that self-esteem may increase the odds of attaining a job in the initial job search, however, it does not necessary act as a protective factor for people disposed for longer periods of labour market exclusion. A study has presented significant gender differences in the development of self-esteem, where males in general have a higher level [22], which supports the results of the present study.

Previous research in a Danish context of Würtz et al. suggested that low sense of coherence in adolescent females (age 12-15) increase the odds of being on social benefits 12 years later [27]. Vastamäki indicated that high sense of coherence increased the chances of getting out of unemployment in a population below the age of 25 [24]. This is in line with the results of the present study indicating a moderate association between high sense of coherence and high LMP for females at age 15 and males at age 18. Danish and Swedish research, in general report age and gender differences in sense of coherence [46], with males reporting a higher level which similarly increases with age. This, together with previously mentioned research displays the knowledge gap in the impact of sense of coherence during adolescence on LMP and the potential differing effect by gender. The present study suggests that the impact of sense of coherence on males and females changes even during the few years of adolescence.

No studies investigating the impact of mastery during adolescence and LMP in early adulthood were found. Several studies have investigated mastery as a mediating factor between unemployment, economic hardship and depression showing strong associations with mastery as a mediating factor [31, 33]. In comparison, the present study showed that high levels of mastery in adolescence was strongly associated with a positive LMP in early adulthood, even when adjusting for the level of depressive symptoms. No significant interaction between depression and mastery was found. Pre-existing literature generally suggests looking at mastery as a mediating factor; however, with the results of the present 
study, perhaps mastery should also be viewed as a psychological resource promoting important life developmental stages such as entering of the labour market.

A limitation of the present study is the categorizations of the exposure variables of psychological resources. Despite the strengths of using well-renowned and validated scales, no normal level of any of the psychological resources has yet been defined. Misclassification of exposure is therefore a potential risk, although sensitivity analyses performed changing the value of categorizations did not alter the results considerably. Additionally, the information of exposure was self-reported, inducing risk of information bias. Considering the prospective design, differential misclassification of exposure in relation to outcome is unlikely as data was collected at baseline (2004) and again in 2007, respectively 14 and 11 years before follow-up. However, there is a possibility that non-differential misclassification could potentially have induced over- or underestimations of the observed associations. Due to the long followup period of 14-years, a gap between data collections occurs where unknown factors to the present study could have biased the outcome.

As previously presented, existing literature regarding LMP often observe LMP through different categorizations. Arguably, cutting high and low LMP at 12 months is a rough categorization and misclassification in relation to the outcome is therefore of high risk. However, as stated earlier the potential bias is expected to be non-differential. The decision of dichotomizing at 12 months was based on a desire to investigate those respondents who had been excluded from the labour market for longer periods of time. Six months was deemed too low a cut-off point considering the age of the study population with many young adults completing education and therefore finding themselves in the transitional period between education and their first job. Supplementary analyses were performed using 6 months of LMP as outcome. The results supported the main findings of the present study, though the associations were weaker compared to 12 months of LMP.

The initial response rate of the West Jutland Cohort was high (83 \% in 2004), though no information on non-responders regarding exposure was available. An earlier study targeting the issues of nonparticipation in the West Jutland Cohort study identified that non-responders are more likely to come from homes with a lower educational and income level [40]. In the present study, it was identified, that LMP was strongly associated with the parents' highest education and moderately associated with their equivalized household income. Selection bias is considered a risk if the association between the psychological resources and LMP would be different between responders and non-responders. However, given the rather large number of respondents in the study population and the broad contrast in the data of exposure variables, those from the lower socioeconomic classes included in the study are expected to be representative and not differ considerably from the non-respondents of lower socioeconomic classes. Selection bias due to non-participation is therefore not of high concern in the present study.

Major strengths of this study are the prospective design and vast questionnaire information providing possibilities of studying associations between psychological, physical and social factors combined with the Danish register information on important life outcomes. The prospective design allowed studying the 
direction of relationship between important life factors. The high initial response rate of $83 \%$ is considered a strength in combination with the use of register-based outcome measures providing complete information, which is considered having a strong validity and coverage of the Danish population [50]. The different data sources minimize the risks of bias in relation to misclassification and information problems. Furthermore, the availability of studying psychological factors at two different stages of adolescence is considered a strength, which provides deeper insight into the development of the changing impact of these exposures.

The external validity and generalizability of the present study is limited by the ramifications of the Danish welfare system. Comparison to countries with different labour market models than Denmark should be made with caution.

\section{Conclusion}

The study found that psychological resources of sense of coherence and mastery seem to act as protective factors of longer labour market exclusion during early adulthood. Self-esteem did not seem to be strongly associated with LMP in early adulthood. Substantial gender differences were observed, indicating that most of these psychological resources have different impacts depending on both age and gender. Further research needs to be conducted focusing on studying how psychological resources operate for both genders at different ages in improving the future focus on psychological resources in childhood and adolescence.

\section{List Of Abbreviations}

LMP: Labour Market Participation

\section{Declarations}

Ethics approval and consent to participate: The study was approved by the Danish Data Protection Agency. According to Danish law (Act on Research Ethics Review of Health Research Projects), available at: www.nvk.dk/english/act-on-research, questionnaire and register-based studies require neither approval by ethical or scientific committees nor written informed consent.

Consent for publication: Not applicable

Availability of data and materials: The datasets used and/or analysed during the current study are available from the authors on reasonable request.

Competing interests: The authors declare that they have no competing interests. 
Funding: This study was funded by The Rockwool Foundation. The funding body did not have any role in the design, collection, analysis, interpretation of data or writing of the manuscript.

Authors' contributions: JHA initiated the study. JDJ designed and performed the analyses and wrote the main paper. TNW and JHA helped analyse and interpret the data and commented on the manuscript at all stages. All authors read and approved the final manuscript.

Acknowledgements: Not applicable

\section{References}

1.Statistics Denmark. (News from Statistics Denmark - Unemployment February 2019 - Work, income and fortune).. Statistics Denmark. 2019 [cited 04-14-2019]. [Available from:

https://www.dst.dk/Site/Dst/Udgivelser/nyt/GetPdf.aspx?cid = 27520]. Danish.

2.Reneflot A, Evensen M. Unemployment and psychological distress among young adults in the Nordic countries: A review of the literature. International Journal of Social Welfare. 2014;23(1):3-15.

3.Paul Kl, Moser K. Unemployment impairs mental health: Meta-analyses. Journal of Vocational Behavior. 2009;74(3):264-82.

4.Viner RM, Ozer EM, Denny S, Marmot M, Resnick M, Fatusi A, et al. Adolescence and the social determinants of health. Lancet (London, England). 2012;379(9826):1641-52.

5.Lundin A, Hemmingsson T. Adolescent predictors of unemployment and disability pension across the life course-a longitudinal study of selection in 49321 Swedish men. IFAU - Institute for Evaluation of Labour Market and Education Policy. 2013(2013:25).

6. Hammer T. Labour market integration of unemployed youth from a life course perspective: The case of Norway 2007. 249-57 p.

7.Røed K, Raaum O. Do Business Cycle Conditions at the Time of Labor Market Entry Affect Future Employment Prospects? 2006. 193-210 p.

8. Helgesson M, Johansson B, Nordqvist T, Lundberg I, Vingard E. Sickness absence at a young age and later sickness absence, disability pension, death, unemployment and income in native Swedes and immigrants. European journal of public health. 2015;25(4):688-92.

9.Franzén EM, Kassman A. Longer-term Labour-market Consequences of Economic Inactivity during Young Adulthood: A Swedish National Cohort Study. Journal of Youth Studies. 2005;8(4):403-24. 
10.Lund T, Andersen JH, Winding TN, Biering K, Labriola M. Negative life events in childhood as risk indicators of labour market participation in young adulthood: a prospective birth cohort study. PloS one. 2013;8(9):e75860-e.

11.Winding TN, Andersen JH. Somatic Complaints in Adolescence and Labour Market Participation in Young Adulthood. Scandinavian journal of public health. 2018; 1-9. DOI: 10.1177/1403494818773515.

12.Lander F, Rasmussen K, Mortensen JT. Social inequalities in childhood are predictors of unemployment in early adulthood. Danish medical journal. 2012;59(3):A4394.

13.Caspi A, Bradley REW, Moffitt TE, Silva PA. Early Failure in the Labor Market: Childhood and Adolescent Predictors of Unemployment in the Transition to Adulthood. American Sociological Review. 1998;63(3):424-51.

14.Due P, Krolner R, Rasmussen M, Andersen A, Trab Damsgaard M, Graham H, et al. Pathways and mechanisms in adolescence contribute to adult health inequalities. Scandinavian journal of public health. 2011;39(6 Suppl):62-78.

15.Winding TN, Labriola M, Nohr EA, Andersen $\mathrm{JH}$. The experience of demanding work environments in younger workers. Occupational medicine (Oxford, England). 2015;65(4):324-30.

16.WHO. Adolescent development [cited 2019 22-05]. Available from: https://www.who.int/maternal_child_adolescent/topics/adolescence/development/en/.

17.Jordan $\mathrm{CH}$, Zeigler-Hill V, Cameron JJ. Self-Esteem. In: Wright JD, editor. International Encyclopedia of the Social \& Behavioral Sciences (Second Edition). Oxford: Elsevier; 2015. p. 522-8.

18.Orth U, Robins RW. The Development of Self-Esteem. Current Directions in Psychological Science. 2014;23(5):381-7.

19.Conger KJ, Williams ST, Little WM, Masyn KE, Shebloski B. Development of mastery during adolescence: the role of family problem-solving. Journal of health and social behavior. 2009;50(1):99114.

20.Lindmark U, Stenström U, Gerdin EW, Hugoson A. The distribution of "sense of coherence" among Swedish adults: A quantitative cross-sectional population study. Scandinavian journal of public health. 2009;38(1):1-8.

21.Myrin B, Lagerström M. Health behaviour and sense of coherence among pupils aged 14-15. Scandinavian Journal of Caring Sciences. 2006;20(3):339-46.

22.Bleidorn W, Arslan RC, Denissen JJ, Rentfrow PJ, Gebauer JE, Potter J, et al. Age and gender differences in self-esteem-A cross-cultural window. Journal of personality and social psychology. 2016;111(3):396-410. 
23.OECD. Transition from school to work: where are the 15-29 year-olds? In: Education at a glance 2016: OECD indicators. OECD Publishing. 2016.

24.Vastamäki J. Sense of Coherence and Unemployment. Academic dissertation, University of ErlangenNuremberg and University of Kuopio.

25.Copeland WE, Wolke D, Shanahan L, Costello EJ. Adult Functional Outcomes of Common Childhood Psychiatric Problems: A Prospective, Longitudinal Study. JAMA psychiatry. 2015;72(9):892-9.

26.Orth U, Robins RW, Widaman KF. Life-span development of self-esteem and its effects on important life outcomes. Journal of personality and social psychology. 2012;102(6):1271-88.

27.Wurtz ET, Fonager K, Mortensen JT. Association between sense of coherence in adolescence and social benefits later in life: a 12-year follow-up study. BMJ Open. 2015;5(1):e006489.

28.R. Waddell G. Labor-Market Consequences of Poor Attitude and Low Self-Esteem in Youth 2006. 6997 p.

29.D. Brown J. High self-esteem buffers negative feedback: Once more with feeling 2010. 1389-404 p.

30.Winefield AH, Tiggemann M, Winefield HR. The psychological impact of unemployment and unsatisfactory employment in young men and women: longitudinal and cross-sectional data. British journal of psychology. 1991;82 (4):473-86.

31.Pudrovska T, Schieman S, Pearlin LI, Nguyen K. The sense of mastery as a mediator and moderator in the association between economic hardship and health in late life. Journal of aging and health. 2005;17(5):634-60.

32.Lachman ME, Weaver SL. The sense of control as a moderator of social class differences in health and well-being. Journal of personality and social psychology. 1998;74(3):763-73.

33.Crowe L, Butterworth P, Leach L. Financial hardship, mastery and social support: Explaining poor mental health amongst the inadequately employed using data from the HILDA survey. SSM - Population Health. 2016;2:407-15.

34.Moksnes UK, Espnes GA, Lillefjell M. Sense of coherence and emotional health in adolescents. Journal of Adolescence. 2012;35(2):433-41.

35.Orth U, Robins RW. Understanding the Link Between Low Self-Esteem and Depression. Current Directions in Psychological Science. 2013;22(6):455-60.

36.Bennetter KE, Clench-Aas J, Raanaas RK. Sense of mastery as mediator buffering psychological distress among people with diabetes. Journal of diabetes and its complications. 2016;30(5):839-44. 
37.Lundberg 0. Childhood conditions, sense of coherence, social class and adult ill health: Exploring their theoretical and empirical relations. Social Science \& Medicine. 1997;44(6):821-31.

38.Twenge J, Campbell WK. Self-Esteem and Socioeconomic Status: A Meta-Analytic Review 2002. 59$71 \mathrm{p}$.

39.Winding TN. The transition from school to work life - Educational attainment and work environment in a Danish youth cohort. Department of Occupational Medicine, Regional Hopstial West Jutland - University Research Clinic: Aarhus University; 2014.

40.Winding TN, Andersen JH, Labriola M, Nohr EA. Initial non-participation and loss to follow-up in a Danish youth cohort: implications for relative risk estimates. Journal of Epidemiology and Community Health. 2014;68(2):137.

41. Hjollund NH, Larsen FB, Andersen JH. Register-based follow-up of social benefits and other transfer payments: accuracy and degree of completeness in a Danish interdepartmental administrative database compared with a population-based survey. Scandinavian journal of public health. 2007;35(5):497-502.

42.Pedersen CB. The Danish Civil Registration System. Scandinavian journal of public health. 2011;39(7 Suppl):22-5.

43.Antonovsky A. Health, stress and coping. Jossey-Bass. 1979.

44.Schooler C, Pearlin LI. The structure of coping. J Health SocBehav. 1978;Vol. 22.

45.Rosenberg M. The self concept: Source, product and social force. Soc Psychol Sociol Perspect. 1979.

46.Eriksson M, Lindström B. Validity of Antonovsky's sense of coherence scale: a systematic review. Journal of Epidemiology and Community Health. 2005;59(6):460.

47.Turner RJ, Lloyd DA, Roszell P. Personal Resources and the Social Distribution of Depression. American Journal of Community Psychology. 1999;27(5):643-72.

48.Statistics Denmark. Documentation of statistics for Income Statistics 2016 Statistics Denmark [cited 2019 04-10]. Available from: http://www.dst.dk/Site/Dst/SingleFiles/kvaldeklbilag.aspx?filename = bf42084f-2efb-4091-a5e1-e196f1df4e98Income_Statistics_2016. Danish.

49.Baadsgaard M, Quitzau J. Danish registers on personal income and transfer payments. Scandinavian journal of public health. 2011;39(7 Suppl):103-5.

50.Jensen VM, Rasmussen AW. Danish Education Registers. Scandinavian journal of public health. 2011;39(7 Suppl):91-4.

51.Bjorner JB, Thunedborg K, Kristensen TS, Modvig J, Bech P. The Danish SF-36 Health Survey: translation and preliminary validity studies. Journal of clinical epidemiology. 1998;51(11):991-9. 
52.Fendrich M, Weissman MM, Warner V. Screening for depressive disorder in children and adolescents: Validating the center for epidmiologic studees depression scale for children. American Journal of Epidemiology. 1990;131(3):538-51.

53.Newcomb MD, Huba GJ, Bentler PM. A multidimensional assessment of stressful life events among adolescents: Derivation and correlates. Journal of Health and Social Behavior. 1981;22(4):400-15. 